\title{
ABSTRACTS
}

\section{A METHODOLOGICAL STUDY CONCERNING AN ANALYSIS OF THE LEARNING MECHANISM : V}

\author{
- Analysis of the series of abilities to learn (2) -
}

by

\author{
Osamaro Nakadake \\ Osaka Prefectural Scientific Educational Center
}

The purpose of this article is to propose an analytical method for series of abilities which lead to the attainment of the same goal. This kind of analysis is very important for programming a course of study and for many other instructional purposes.

Such series may take on various structures. Figures in $(1-1)$ and $(1-2)$ are examples of the structure.

$$
\cdots \cdot \mathrm{A}_{41}
$$

where $A_{i j}$ is a step (a particular ability) in the series

$G$ is the goal of the instruction $A_{p q}$ is the ability higher than $A_{p_{+1}}$. $A_{11}$ directly leads to the attainment of $\mathrm{G}$

Series $(1-1)$ have a systematic structure, but series (1-2) have comparatively complex structure.

The series which have systematic structure like series $(1-1)$ are called complete-multi-series, and the series which have complex structure like series $(1-2)$ are called incomplete-multi-series.

The complete-multi-series $(1-1)$ is analyzed as follows. Suppose that $a_{i j^{*}}$ is an item of an achievement test which measures the ability $A_{i j}$ in series $(1-1)$. The response pattern of a pupil to a battery of items is represented as

$$
\begin{aligned}
& \left(a_{11}, a_{21}, \cdots \cdots, a_{i j}, \cdots, \cdot\right) \\
& \text { where } a=1 \text { or } 0 \\
& 1 \text { designates "pass" and } 0 \text { "fail" in item } a \text {. }
\end{aligned}
$$

If a pattern $\mathrm{X}$ is such that $a_{i_{1}}=1$ and $a_{i_{2}}=0, \mathrm{Y}$ is $a_{i_{1}}=0$ and $a_{i_{2}}=1$, and $Z$ is $a_{i_{1}}=1$ and $a_{i_{2}}=1$, we call $Z$ a duplicated pattern of $X$ and $Y$.

We shall consider only those who passed $a_{11}$, i.e., those who attained $G$. There will be difference in response even among them. A pupil may attain $G$ while failing in some of the earlier steps, and another pupil may attain the same $G$ while failing in different set of steps. These patterns will show alternative routs for attaining $\mathrm{G}$.

Response patterns which have led to $(G)$ and yet have no duplicated structure between each other, are called Mutually Independent Serial Response Patterns.

Let $\mathrm{R}\left(a_{i}, x_{i}\right)$ be the quantity of Mutually Independent Serial Response Pattern with $a_{i j}=1$, then

$$
\begin{gathered}
\mathrm{R}\left(a_{i j, k}\right)=2^{k^{-} i}{ }_{i-1} \mathrm{C}_{j-1} \\
\text { where } k \text { is the maximum value of }(i) \text { in } \\
\text { series }(1-1) \text {, and it is called the } \\
\text { length of series }(1-1) .
\end{gathered}
$$

$$
{ }_{i} \mathrm{C}_{n}=\frac{l(l-1) \cdots \cdots(l-n+1)}{1 \cdot 2 \cdot \cdots \cdots \cdot(n-1) n}
$$

